\title{
Assessment of professional nursing governance and hospital magnet components at Alexandria Medical Research Institute, Egypt
}

\author{
Ebtsam Aly Abou Hashish*1,2, Sally Mohamed Fargally ${ }^{1}$ \\ ${ }^{1}$ Nursing Administration Department, Faculty of Nursing, Alexandria University, Alexandria, Egypt \\ ${ }^{2}$ College of Nursing, King Saud bin Abdul-Aziz University for Health Sciences, Jeddah, KSA
}

Received: September 3, 2017

Accepted: October 10, 2017

Online Published: October 30, 2017

DOI: $10.5430 /$ jnep.v8n3p37

URL: https://doi.org/10.5430/jnep.v8n3p37

\begin{abstract}
Background and objective: In the context of a rapidly evolving health care system, health care institutions strive to set a path towards an excellent professional practice environment. Since improving clinical nurse work environments is a major issue faced by nurse executives and administrators, they become challenged to establish nursing governance models, and leadership practices so that clinical nurses can engage in the work processes and relationships that are empirically linked to quality patient outcomes. The main aim of this study was to assess the current status of professional nursing governance and hospital magnet components at Alexandria Medical Research Institute, Egypt.

Methods: A descriptive research design was conducted at Alexandria Medical Research Institute hospital, using a convenience sample $(\mathrm{N}=220)$ that composed of two groups including; all hospital medical administrators $(\mathrm{n}=10)$ and hospital nursing workforce $(n=210)$. Index of Professional Nursing Governance Questionnaire (IPNGQ) and Magnet Hospital Forces Interview were proved valid and reliable to measure study variables.

Results: The overall mean score of professional nursing governance was $(187.59 \pm 63.74)$ reflected that staff nurses practice the first level of nursing shared governance (primarily nursing management who take the decision with some staff input). In addition, both medical administrators and nursing staff identified the hospital has a good structure, nursing leadership practices that support shared governance and magnet recognition. Structural equation model and correlation analysis revealed a positive association between overall professional nursing governance and hospital magnet components $(p<.05)$.

Conclusions and recommendations: The study emphasized the hospital administrators' important role for providing supportive organizational structures and leadership practices for increasing participation of nursing staff in work design, problem-solving, conflict resolution, committees and organizational decision-making as "key ingredients to a successful organization" in turn, lead to a healthy and magnet-like work environment. Training programs for nurses' professional development are recommended which enhance and increases their autonomy and empowerment.
\end{abstract}

Key Words: Professional nursing governance, Magnet components, Shared governance, Nursing staff, Hospitals

\section{INTRODUCTION}

In today's complex healthcare settings, several challenges are faced such as nursing shortage, decreased workforce, in- creased patient acuities, and increased regulations that led to nurses' workload, job dissatisfaction, and less time spent at the bedside. These challenges increase nurses' responsibili-

\footnotetext{
*Correspondence: Ebtsam Aly Abou Hashish; Email: ebtsam_ss@hotmail.com; Address: Nursing Administration Department, Faculty of Nursing, Alexandria University, Alexandria, Egypt.
} 
ties and accountabilities but do not add power or authority to address needed changes to affect nursing practice. ${ }^{[1-3]}$ Healthcare executives and leaders realize that quality care is best delivered by staff nurses who are committed to the organization and empowered to practice their profession with no restraints and full autonomy through the implementation of professional nursing governance and shared governance models and creating an attractive work environment. ${ }^{[3,4]}$

Magnet reflects the highest recognition of excellence in the delivery of nursing service provided in a professional practice environment, which promotes quality and evidence based practice and result in positive patient outcomes. ${ }^{[5,6]}$ Healthcare organizations striving for the achievement of nursing excellence in professional practice through including and supporting magnet recognition elements and forces and shared governance in their strategic plan. ${ }^{[1]}$

\subsection{Background on study variables}

\subsubsection{Professional Nursing Governance (PNG)}

Hess $^{[7,8]}$ defined professional nursing governance as a multidimensional concept that encompasses the structure and process through which professional nurses direct, control and regulate the many goal-oriented efforts of their professional practice and influence the organizational context in which it occurs through organizational recognition, facilitating structures, the liaison of information and the alignment of goals. Professional nursing shared governance is the extension of power, control, and authority to the frontline staff nurses over their clinical practice. ${ }^{[7,8]}$

Hess $^{[8]}$ developed the Index of Professional Nursing Governance (IPNG) to measure professional nursing governance. He identified six dimensions in the IPNG that characterize governance within the organization namely: control over practice; specifically, patient care policies and procedures, quality and care products, staffing, education, and research in practice. Influence over resources which relates to who influences resources that support professional practices within the organization. Control over personnel which addresses the organizational structure in place related to hiring, evaluating performance, disciplinary actions, and recommendation of salaries and benefits. Participation in committee structures which reflects the organizational structure in place to support participation in committees. Access to information including budget and expenses, goals and objectives, organizations finances, and opinions of staff, patients, and physicians. In addition to the ability to set goals and negotiate the resolution of conflict at different organizational levels. ${ }^{[8]}$ IPNG can be used for obtaining baseline and evaluative data for the implementation of nursing shared governance innovation and its outcome. ${ }^{[7,8]}$

\subsubsection{Magnet recognition program}

Professional nursing shared governance model is a key component in structuring professional nursing practice to achieve magnet recognition and nursing excellence. ${ }^{[9]}$ The American Nurses Credentialing Center (ANCC) developed the Magnet Recognition Program (New Magnet Model) in order to recognize quality patient care, nursing excellence and innovations in professional nursing practice. ${ }^{[6]}$ This New Magnet Model aligns the 14 Forces of magnetism with five model components could establish the essential elements of excellence in nursing to attract nurses to work in a particular hospital, make them want to stay and enhance their job satisfaction. ${ }^{[10]}$

The first component of the magnet model is transformational leadership which centers on how leadership establishes a vision (including values, beliefs, and behaviors) that will sustain the organization in the future. Magnet forces related to this component are; quality of nursing leadership and management style. Structural empowerment reflects the second component, which examines how the organization's structure and relationship support innovation and professional practice and embody its mission, vision, and values. Five forces align with this component; organizational structure, personnel policies and programs, community and the healthcare organization, image of nursing and professional development. ${ }^{[6,10]}$

The third component is exemplary professional practice, which encompasses the creation of a vision and system that foster a professional nursing practice. It also supports the use of knowledge and evidence to generate the best possible outcomes for patients, families, communities and the healthcare team. This component incorporates the forces of; professional models of care, consultation and resources, autonomy, nurses as teachers and interdisciplinary relationships. New knowledge, innovations and improvements make up the fourth component that targets the importance of the development, implementation and sharing of new knowledge and best practices. This component includes quality improvement force. The fifth component is empirical quality outcomes which help to direct the organization's focus on how care is provided and the achieved outcomes. Quality of care serves as a founding force for this component. ${ }^{[6,10]}$

\subsection{Significance of the study}

During the last years, several studies have been published in West which focused on assessing nurses' perception of shared governance. ${ }^{[1,11-13]}$ These studies reflected variation in nurses' perception and participation in their professional nursing practice and governance and recommended further investigation and measurement of professional nursing governance in wider and different contexts. 
In Egypt, many studies conducted for assessing forces of magnetism in hospital setting. A study was conducted by Abd Elkader ${ }^{[14]}$ assessed the magnet professional forces as perceived by administrators and nursing staff. Also, a study was conducted by Abd Elrazek ${ }^{[15]}$ investigated the relationship between nurses' perception toward the essentials of magnetism and patients' safety culture which found a positive correlation between them. Furthermore, a study was done by El Bialy and Abd Elaal ${ }^{[16]}$ to assess the perception of essentials of magnetism indicated that staff nurses perceived a moderate level of magnetism. ${ }^{[14-16]}$ Another study conducted by Ahmed ${ }^{[17]}$ found a positive correlation between shared governance and nurses work satisfaction.

Despite much interest in measuring the professional nursing governance, there is little research published that has explicitly evaluated it. Exactly to what extent the professional nursing governance baseline assessment is currently unknown. It is important to evaluate the current status of professional nursing governance at hospitals to inform nurse leaders of concerns and issues within the current hospital and nursing structure and provide them priority-focused areas of improvement for the achievement of nursing excellence. ${ }^{[8]}$

Baseline assessment of the degree of professional nursing governance, utilizing the Index of Professional Nursing Governance and the ANCC Magnet framework is a timely topic for research and can help in identifying gap analysis and improvement strategies which may help in improving the quality of nursing care, achieving excellence in nursing profession, raising the community confidence in nursing graduates' performance, improve marketing and reputation of hospitals and nursing image both nationally and internationally. ${ }^{[10,18,19]}$

\subsection{Aim of the study}

(1) The main aim of this study was to assess the current status of professional nursing governance and magnet components and related forces of magnetism at Alexandria Medical Research Institute hospital.

(2) The secondary purpose is to identify the nature of the relationship between professional nursing governance and hospital magnet components.

\subsection{Research questions}

(1) What is the current status of professional nursing governance and magnet components and related forces of magnetism at Alexandria Medical Research Institute Hospital?

(2) What is the relationship between professional nursing governance and hospital magnet components?

\section{Materials AND Method}

\subsection{Research design and setting}

A descriptive research design was used in this study. The study was conducted in all hospital departments of Medical Research Institute. This hospital is affiliated to Alexandria University, Egypt, and provides comprehensive medical and surgical services for patients, teaching services for medical and nursing students in addition to research activities. Medical Research Institute is a well-known setting that initiates the investment of governance concepts and principles through training of health care professionals in the Health Governance Unit, Alexandria University. The hospital included seven departments namely: surgical, medical, oncology, anesthesia, blood diseases, laboratories, and x-ray departments with a capacity of 300 beds.

\subsection{Participants}

The subjects of the study comprised a convenience sample of hospital staff members $(\mathrm{N}=220)$ who agreed to participate in the study. Two groups were included: The first group represented all hospital medical administrators including hospital director and all departments' head $(\mathrm{n}=10)$. The second group composed of hospital nursing work force $(\mathrm{N}=210)$ including: all nursing administrators $(n=23)$ representing; the director of nursing services, an assistant director of nursing services, a nurse supervisor, and 20 first-line nurse managers and all staff nurses $(\mathrm{n}=187)$ including: an infection control/clinical nurse educator, a quality coordinator nurse and direct care staff nurses working in all hospital departments.

\subsection{Study measurements}

Data for this study were collected using the following two tools:

Tool One: Index of Professional Nursing Governance Questionnaire (IPNGQ)

IPNGQ was developed by Hess ${ }^{[8]}$ to assess the degree of professional nursing governance as perceived by nursing personnel on a continuum from traditional, to shared, and self-governance. It included six main dimensions and 86 items of professional governance including; control over professional practice (16 items), influence over resources (13 items), control over personnel (22 items), participation in committee structures (12 items), access to information (15 items), and ability to set goals and conflict resolution (8 items). Scores for the full scale and subscales were computed by summing the responses of each respondent across all 86 items or items comprising each subscale. The score was based on a 5-point Likert scale that ranged from 1 to 5 , including: 1 = nursing management/administration only, 2 $=$ primarily nursing management/administration with some 
staff nurse input, $3=$ equally shared by staff nurses and nursing management/administration, $4=$ primarily staff nurses with some nursing management/administration, and $5=$ staff nurses only.

Regarding the scoring of IPNG, the range from 86-172 of total scores was reflecting (traditional) management decisionmaking environment. An environment which utilized professional nursing (shared) decision-making between staff nurses.

Management would have an IPNG range of 173-257 if the decision was primarily taken by nursing management with some nursing staff input, while an IPNG score of 258 indicated (an equally shared) governance, and if an IPNG range of 259-344 it indicated that the decision was primarily taken by nursing staff with some nursing management input. If staff nurses were the decision-making group (selfgovernance), IPNG range would be from $345-430 .{ }^{[7,8]}$

\section{Tool Two: The magnet hospital forces interview}

The Magnet Hospital Forces Interview tool that was developed and validated by Abd Elkader ${ }^{[14]}$ used for assessing the hospital magnet components and its forces of magnetism as perceived by medical administrators, nursing administrators, and staff nurses. The Magnet Hospital Forces Interview tool was divided into 128 items under the 14 Forces of Magnetism namely: quality of nursing leadership (19 items), organizational structure (5 items), management style (10 items), personnel policies and programs ( 9 items), method of patient care assignment (5 items), quality of nursing care (11 items), quality improvement of nursing care (10 items), consultation and resources (5 items), nursing autonomy (5 items), community and health care organization (4 items), nursing role as teachers (10 items), nursing image (10 items), interdisciplinary relationships (10 items), and professional development (15 items). Responses were measured on five-point Likert-Scale ranged from 1 to 5: " 1 " denoted strongly disagree where " 5 " denoted strongly agree. Subject responses were calculated in scoring system as following; low magnet recognition $(<33 \%)$, moderate magnet recognition (33\%$66 \%$ ) and high magnet recognition $(\geq 66 \%)$.

In addition, a demographic characteristics form of all study subjects included questions related to (gender, age, educational qualification, job position, years of experience and attended training programs).

\subsection{Validity and reliability}

The study questionnaires were translated into Arabic and examined for translation, content validity and relevance to be suited for Egyptian culture by 5 experts in the field of study from different academic departments at the Faculty of
Nursing, Alexandria University. Then, tools were back translated into English by language experts. The back-translations were reviewed by researchers and members of the Jury to ensure accuracy and minimize potential threats to the study's validity. Also, a pilot study was done on $10 \%$ of staff nurses that were excluded from the study participants to; check and ensure clarity and applicability of the tool; identify obstacles and problems that may be encountered during data collection. Accordingly, little rewording was done in the questionnaires. In addition, the questionnaires were tested for reliability using Cronbach's alpha coefficient test, to measure the internal consistency of the items composing each dimension of the two tools, both questionnaires were proved strongly reliable where $\alpha=0.970$ and 0.989 for IPNG, and Magnet Hospital Forces Interview tools, respectively at $p \leq .05$.

\subsection{Data collection}

A written approval was obtained from the administrators of the identified setting to collect study data. Permission for using Magnet Hospital Forces Interview tool was got from the primary author. Data collection for this study was collected by the researchers using self-administered questionnaires and an individual interview with all subjects at study setting as follows: a) IPNG survey questionnaire was used for assessment of the current professional nursing governance that was distributed among nursing administrators and staff nurses. b) Individual interview with medical administrators, nursing administrators and all staff nurses using The Magnet Hospital Forces Interview was conducted to assess the magnet components and related forces of magnetism in the hospital. Data collection were conducted from May 2016 to January 2017.

\subsection{Ethical considerations}

Approval was obtained from the Ethics Committee of the Faculty of Nursing, Alexandria University. The privacy and confidentiality of data were maintained and assured by getting participants' consent to participate in the research before data collection. Anonymity of participants was granted.

\subsection{Data analysis}

Data were coded and entered the statistical package of social science (SPSS), version 20. Frequency and percentages were used for describing demographics characteristics. Arithmetic mean and standard deviation (SD) were used as measures of central tendency and dispersion respectively, for quantifying variables under the study. Chi-square/Monte Carlo test was used to compare between different groups, and Pearson correlation coefficient analysis ( $r$ ) was used to test the nature of the relationship between the study variables. Structural equation model was used for determining the correlation 
between Magnet model components (independent variables) and professional nursing governance (outcome variable) to identify the unique direct and indirect (Path relations) effect for each latent variable over outcome variable keeping all other relations constant. The magnitude of effect identified by a standardized regression coefficient for each latent variable. All statistical analyses were performed using an alpha error of $p$ value $\leq .05$ which considered significant.

\section{RESUlt}

\subsection{Participants demographic characteristics}

Participants demographic characteristics reveals that $95.5 \%$ of the study subjects were female, while $4.5 \%$ of them were male. The highest percentage of study subjects $(40.5 \%)$ were in the age group of less than 30 years old, all of them were nursing staff; and the least percentage of study subjects $(5.5 \%)$ were in the age group more than 50 years old, represented as $4.8 \%$ among nursing staff and $20 \%$ of medical administrators. For educational qualification, all medical administrators had post doctorate degrees in medicine. About two third of nurses $(60 \%)$ had a technical diploma of secondary nursing school while $18.1 \%$ had a bachelor of nursing science. Regarding nursing job position, the highest percentage of nursing staff $(88.1 \%)$ were working as bedside nurses, $9.5 \%$ of them were working as first-line nurse managers. In addition to the director of nursing, an assistant director of nursing, a nurse supervisor, an infection control/ clinical nurse educator, and a quality coordinator nurse. For years of hospital working experience, about one third of study subjects $(31.8 \%)$ had more than 20 years of hospital working experience, represented as $29 \%$ among nursing staff and $90 \%$ of medical administrators. While $15.5 \%$ of nursing staff had less than 5 years of experience.

As regard attending training programs, only one of medical administrators (10\%) attended a health governance training program. For nursing staff, $2.8 \%, 5.7 \%$ and $1.4 \%$ of them attended quality training, infection control, hospital management, and health governance training programs, respectively (see Table 1).

\subsection{Assessment of professional nursing governance at Alexandria Medical Research Institute Hospital}

Table 2 shows that the mean score of nursing staff assessment toward professional nursing governance was $187.59 \pm 63.74$ which indicates that nurses practice the first level of nursing shared governance (primarily nursing management who take the decision with some staff input). The highest mean score of professional nursing governance was related to control over professional practice $(41.02 \pm 12.68)$. While the lowest mean score was related to goal setting and conflict resolution

Published by Sciedu Press
$(18.20 \pm 8.52)$

\subsection{Assessment of magnet components and related forces as perceived by medical administrators and nursing staff at Alexandria Medical Research Insti- tute Hospital}

Table 3 illustrates that there was a statistically significant difference between medical administrators and nursing staff regarding their perceptions of overall magnet components and related forces $(p<.001)$. Medical administrators perceived moderate recognition of magnet forces, while about one half of nursing staff perceived high magnet forces recognition. The same trend of the result was reflected in the related forces. Medical administrators perceived moderate structural empowerment and exemplary professional practice while the highest percentages of nursing staff $(52.4 \%, 46.7 \%)$ perceived a high degree of these components, respectively ( $p$ $=.001)$. Significant differences were found between them in the related forces of; community and health care organizations, professional development, methods of patient care assignment, consultation resources, nursing autonomy, nursing role as teachers, and interdisciplinary relationships. Furthermore, medical administrators perceived moderate quality improvement and quality of nursing care, while, about half of nursing staff perceived them as a high $(p \leq .001)$.

\subsection{Correlation between elements of professional nurs- ing governance and hospital magnet components}

Table 4 reveales that there was a significant positive correlation between overall magnet components and control over professional practice $(r=0.181, p=.009)$. Also, there was a statistical significant positive correlation between control over professional practice and each of the following magnet components; structural empowerment $(r=0.219, p=.001)$, exemplary professional practice $(r=0.203, p=.003)$, and quality of nursing care $(r=0.152, p=.028)$. On the other hand, results revealed a statistically significant negative correlation between participation in committee structure and New knowledge, innovations and improvements (Quality Improvement $)(r=-0.137, p=.048)$ and between goal setting and conflict resolution and empirical quality outcomes (quality of nursing care) $(r=-0.133, p=.050)$.

\subsection{Standardized regression weight for the relationship between professional nursing governance and mag- net components}

Table 5 showes that there was a strong positive association between overall professional nursing governance and transformational leadership; as the increase in transformational leadership by one standardized point score associated with an increase in professional nursing governance by 0.931 
standardized point score. Also, there was an intermediate later variables by one standardized point score associated significant positive correlation between overall professional with an increase in overall professional nursing governance nursing governance and each of exemplary professional prac- by 0.73 and 0.75 standardized point score, respectively. tice and empirical quality outcomes; as the increase in these

Table 1. Demographic characteristics of all study subjects at Alexandria Medical Research Institute Hospital $(\mathrm{N}=220)$

\begin{tabular}{|c|c|c|c|c|c|c|}
\hline \multirow[t]{2}{*}{ Demographic characteristics } & \multicolumn{2}{|c|}{$\begin{array}{l}\text { Medical Administrators } \\
(\mathrm{n}=10)\end{array}$} & \multicolumn{2}{|c|}{$\begin{array}{l}\text { Nursing Staff } \\
(\mathrm{n}=210)\end{array}$} & \multicolumn{2}{|c|}{$\begin{array}{l}\text { Total } \\
(\mathrm{N}=220)\end{array}$} \\
\hline & No. & $\%$ & No. & $\%$ & No. & $\%$ \\
\hline \multicolumn{7}{|l|}{ Gender } \\
\hline Male & 7 & 70.0 & 3 & 1.4 & 10 & 4.5 \\
\hline Female & 3 & 30.0 & 207 & 98.6 & 210 & 95.5 \\
\hline \multicolumn{7}{|l|}{ Age (years) } \\
\hline Less than 30 & 0 & 0.0 & 89 & 42.4 & 89 & 40.5 \\
\hline From 30-40 & 0 & 0.0 & 69 & 32.9 & 69 & 31.4 \\
\hline From 41-50 & 8 & 80.0 & 42 & 20.0 & 50 & 22.7 \\
\hline More than 50 & 2 & 20.0 & 10 & 4.8 & 12 & 5.5 \\
\hline $\begin{array}{l}\text { Educational qualifications of medical administrators (post } \\
\text { doctorate degrees in medicine) }\end{array}$ & 10 & 100.0 & - & - & - & - \\
\hline \multicolumn{7}{|l|}{ Educational qualifications of nursing } \\
\hline Bachelor of Nursing Science & - & - & 38 & 18.1 & - & - \\
\hline Diploma of Technical Institute of Nursing & - & - & 33 & 15.7 & - & - \\
\hline Diploma of Secondary School of Nursing & - & - & 126 & 60.0 & - & - \\
\hline Others & - & - & 13 & 6.2 & - & - \\
\hline \multicolumn{7}{|l|}{ Nursing job position } \\
\hline Director of Nursing & & & 1 & 0.48 & - & - \\
\hline Assistant Director of Nursing & & & 1 & 0.48 & - & - \\
\hline Nurse Supervisor & & & 1 & 0.48 & - & - \\
\hline Infection Control/Clinical Nurse Educator & & & 1 & 0.48 & - & - \\
\hline Quality Coordinator Nurse & & & 1 & 0.48 & - & - \\
\hline First-Line Nurse Managers & & & 20 & 9.5 & - & - \\
\hline Bedside Nurse & & & 185 & 88.1 & - & - \\
\hline \multicolumn{7}{|l|}{ Hospital working experience years } \\
\hline Less than 5 years & 0 & 0.0 & 34 & 16.2 & 34 & 15.5 \\
\hline From 5 to 10 years & 0 & 0.0 & 50 & 23.8 & 50 & 22.7 \\
\hline From 11 to 20 years & 1 & 10.0 & 65 & 31.0 & 66 & 30.0 \\
\hline More than 20 years & 9 & 90.0 & 61 & 29.0 & 70 & 31.8 \\
\hline \multicolumn{7}{|l|}{ Attended training programs } \\
\hline No & 9 & 90.0 & 190 & 90.5 & 199 & 90.5 \\
\hline Quality program & 0 & 0.0 & 6 & 2.8 & 6 & 2.7 \\
\hline Infection control & 0 & 0.0 & 12 & 5.7 & 12 & 5.5 \\
\hline Hospital management & 0 & 0.0 & 3 & 1.4 & 3 & 1.4 \\
\hline Health governance & 1 & 10.0 & 3 & 1.4 & 4 & 1.8 \\
\hline
\end{tabular}

Notes. SD: Standard Deviation

Table 2. Mean distribution of nursing staff assessment of Professional Nursing Governance at Alexandria Medical Research Institute Hospital

\begin{tabular}{lll}
\hline Elements of Professional Nursing Governance (PNG) & Mean & SD \\
\hline - Control over Professional Practice & 41.02 & 12.68 \\
- Control over Personnel & 37.08 & 16.63 \\
- Influence over Resources & 34.29 & 10.40 \\
- Participation in Committee Structures & 24.78 & 11.74 \\
- Access to Information & 32.22 & 13.46 \\
- Goal Setting and Conflict Resolution & 18.20 & 8.52 \\
Overall mean score of Professional Nursing Governance (PNG) & $187.59^{*}$ & 63.74 \\
\hline
\end{tabular}

Notes. SD: Standard Deviation; * Shared governance: - Primarily nursing management with some nursing staff input (173-257) 
Furthermore, there was a positive weak relationship between standardized point score. On the other hand, the negative overall professional nursing governance and new knowledge, relationship indicates that the increase in structural empowinnovations, and improvement, as the increase in this com- erment by one standardized point score associated with a deponent by one standardized point score associated with an crease in overall professional nursing governance by -0.163 increase in overall professional nursing governance by 0.309 standardized point score.

Table 3. Assessment of magnet components and related forces as perceived by medical administrators and nursing staff at Alexandria Medical Research Institute Hospital

\begin{tabular}{|c|c|c|c|c|c|c|c|c|c|c|c|c|c|}
\hline \multirow{3}{*}{ Magnet components and related forces } & \multicolumn{6}{|c|}{$\begin{array}{l}\text { Medical Administrators } \\
(n=10)\end{array}$} & \multicolumn{6}{|c|}{$\begin{array}{l}\text { Nursing staff } \\
(n=210)\end{array}$} & \multirow{3}{*}{${ }^{\mathrm{MC}} p$} \\
\hline & \multicolumn{2}{|l|}{ Low } & \multicolumn{2}{|c|}{ Moderate } & \multicolumn{2}{|c|}{ High } & \multicolumn{2}{|c|}{ Low } & \multicolumn{2}{|c|}{ Moderate } & \multicolumn{2}{|c|}{ High } & \\
\hline & No. & $\%$ & No. & $\%$ & No. & $\%$ & No. & $\%$ & No. & $\%$ & No. & $\%$ & \\
\hline Transformational leadership & 1 & 10.0 & 1 & 10.0 & 8 & 80.0 & 23 & 11.0 & 94 & 44.8 & 93 & 44.3 & .057 \\
\hline Quality of Nursing leadership & 1 & 10.0 & 1 & 10.0 & 8 & 80.0 & 24 & 11.4 & 74 & 35.2 & 112 & 53.3 & .237 \\
\hline Management Style & 0 & 0.0 & 2 & 20.0 & 8 & 80.0 & 37 & 17.6 & 97 & 46.2 & 76 & 36.2 & $.031^{*}$ \\
\hline Structural empowerment & 0 & 0.0 & 10 & 100.0 & 0 & 0.0 & 13 & 6.2 & 87 & 41.4 & 110 & 52.4 & $.001^{*}$ \\
\hline Organizational Structure & 0 & 0.0 & 2 & 20.0 & 8 & 80.0 & 35 & 16.7 & 74 & 35.2 & 101 & 48.1 & .174 \\
\hline Personnel Policies and Programs & 0 & 0.0 & 2 & 20.0 & 8 & 80.0 & 38 & 18.1 & 62 & 29.5 & 110 & 52.4 & .252 \\
\hline $\begin{array}{l}\text { Community and Health Care } \\
\text { Organization }\end{array}$ & 0 & 0.0 & 10 & 100.0 & 0 & 0.0 & 42 & 20.0 & 61 & 29.0 & 107 & 51.0 & $<.001 *$ \\
\hline Nursing Image & 0 & 0.0 & 2 & 20.0 & 8 & 80.0 & 13 & 6.2 & 70 & 33.3 & 127 & 60.5 & .634 \\
\hline Professional Development & 0 & 0.0 & 10 & 100.0 & 0 & 0.0 & 23 & 11.0 & 49 & 23.3 & 138 & 65.7 & $<.001^{*}$ \\
\hline Exemplary professional practice & 0 & 0.0 & 10 & 100.0 & 0 & 0.0 & 35 & 16.7 & 77 & 36.7 & 98 & 46.7 & $<.001 *$ \\
\hline Methods of Patient Care assignment & 2 & 20.0 & 8 & 80.0 & 0 & 0.0 & 13 & 6.2 & 64 & 30.5 & 133 & 63.3 & $<.001 *$ \\
\hline Consultation Resources & 8 & 80.0 & 2 & 20.0 & 0 & 0.0 & 51 & 24.3 & 58 & 27.6 & 101 & 48.1 & $<.001 *$ \\
\hline Nursing Autonomy & 0 & 0.0 & 10 & 100.0 & 0 & 0.0 & 49 & 23.3 & 62 & 29.5 & 99 & 47.1 & $<.001 *$ \\
\hline Nursing Role as Teachers & 0 & 0.0 & 10 & 100.0 & 0 & 0.0 & 46 & 21.9 & 57 & 27.1 & 107 & 51.0 & $<.001^{*}$ \\
\hline Interdisciplinary Relationships & 2 & 20.0 & 0 & 0.0 & 8 & 80.0 & 15 & 7.1 & 84 & 40.0 & 111 & 52.9 & $.013^{*}$ \\
\hline $\begin{array}{l}\text { New knowledge, innovations and } \\
\text { improvements (Quality Improvement) }\end{array}$ & 0 & 0.0 & 10 & 100.0 & 0 & 0.0 & 19 & 9.0 & 85 & 40.5 & 106 & 50.5 & $.001^{*}$ \\
\hline $\begin{array}{l}\text { Empirical quality outcomes (Quality of } \\
\text { Nursing Care) }\end{array}$ & 0 & 0.0 & 10 & 100.0 & 0 & 0.0 & 25 & 11.9 & 73 & 34.8 & 112 & 53.3 & $<.001 *$ \\
\hline $\begin{array}{l}\text { Overall Magnet components (Nursing } \\
\text { Excellence) }\end{array}$ & 0 & 0.0 & 10 & 100.0 & 0 & 0.0 & 14 & 6.7 & 89 & 42.4 & 107 & 51.0 & $.001 *$ \\
\hline
\end{tabular}

Table 4. Correlation between elements of professional nursing governance and hospital magnet components

\begin{tabular}{|c|c|c|c|c|c|c|c|c|}
\hline $\begin{array}{l}\text { Magnet components } \\
\text { (Nursing Excellence) }\end{array}$ & & $\begin{array}{l}\text { Control over } \\
\text { professional } \\
\text { practice }\end{array}$ & $\begin{array}{l}\text { Control } \\
\text { over } \\
\text { personnel }\end{array}$ & $\begin{array}{l}\text { Influence } \\
\text { over } \\
\text { resources }\end{array}$ & $\begin{array}{l}\text { Participati } \\
\text { on in } \\
\text { committee } \\
\text { structure }\end{array}$ & $\begin{array}{l}\text { Access to } \\
\text { informa- } \\
\text { tion }\end{array}$ & $\begin{array}{l}\text { Goal } \\
\text { setting }\end{array}$ & $\begin{array}{l}\text { Overall } \\
\text { professional } \\
\text { nursing } \\
\text { governance }\end{array}$ \\
\hline \multirow{2}{*}{ Transformational leadership } & $r$ & 0.092 & 0.108 & 0.061 & -0.011 & 0.015 & 0.008 & 0.059 \\
\hline & $p$ & 0.186 & 0.119 & 0.379 & 0.878 & 0.829 & 0.904 & 0.393 \\
\hline \multirow{2}{*}{ Structural empowerment } & $r$ & 0.219 & 0.080 & 0.069 & -0.021 & -0.037 & -0.074 & 0.045 \\
\hline & $p$ & $0.001 *$ & 0.246 & 0.321 & 0.767 & 0.595 & 0.283 & 0.519 \\
\hline \multirow{2}{*}{$\begin{array}{l}\text { Exemplary professional } \\
\text { practice }\end{array}$} & $r$ & 0.203 & 0.102 & 0.062 & -0.031 & -0.045 & -0.065 & 0.045 \\
\hline & $p$ & $0.003 *$ & 0.139 & 0.373 & 0.657 & 0.519 & 0.352 & 0.519 \\
\hline \multirow{2}{*}{$\begin{array}{l}\text { New knowledge, innovations } \\
\text { and improvements (Quality } \\
\text { Improvement) }\end{array}$} & $r$ & 0.073 & 0.013 & -0.010 & -0.137 & -0.075 & -0.131 & -0.047 \\
\hline & $p$ & 0.296 & 0.851 & 0.884 & $0.048^{*}$ & 0.280 & 0.058 & 0.495 \\
\hline \multirow{2}{*}{$\begin{array}{l}\text { Empirical quality outcomes } \\
\text { (Quality of Nursing Care) }\end{array}$} & $r$ & 0.152 & 0.076 & 0.043 & -0.101 & -0.067 & -0.133 & -0.001 \\
\hline & $p$ & $0.028 *$ & 0.273 & 0.539 & 0.146 & 0.337 & $0.050 *$ & 0.992 \\
\hline \multirow{2}{*}{$\begin{array}{l}\text { Overall magnet components } \\
\text { (Nursing Excellence) }\end{array}$} & $r$ & 0.181 & 0.093 & 0.060 & -0.042 & -0.037 & -0.069 & 0.038 \\
\hline & $p$ & $0.009^{*}$ & 0.178 & 0.386 & 0.544 & 0.596 & 0.318 & 0.580 \\
\hline
\end{tabular}

Note. $r$ : Pearson coefficient ${ }^{*}$ : Statistically significant at $p \leq .05$ 
Table 5. Standardized regression weight for the relationship between professional nursing governance and hospital magnet components

\begin{tabular}{llll}
\hline Dependent variable (PNG) & & Independent variable (Magnet Components) & Estimate \\
\hline Professional nursing governance & $<---$ & Transformational leadership & .931 \\
Professional nursing governance & $<---$ & Structural empowerment & -.163 \\
Professional nursing governance & $<---$ & Exemplary professional practice & .730 \\
Professional nursing governance & $<---$ & New knowledge, innovations, and improvement & .309 \\
Professional nursing governance & $<---$ & Empirical quality outcomes & .750 \\
\hline
\end{tabular}

Note. Estimate: Standardized (Coefficient) regression weight, *Statistically significant at $p \leq .05$.

Weak relationship Estimate $=(0.1<0.5)$, Intermediate relationship Estimate $=(0.5<0.9)$, Strong relationship Estimate $=(\geq 0.9)$

\section{Discussion}

\subsection{Professional nursing governance at Alexandria Med- ical Research Institute Hospital}

Interesting for the present study, the assessment of professional nursing governance indicated that nurses practice the first level of nursing shared governance which reflected that the nursing-related decisions in this hospital were taken primarily by nursing management with some staff nurses input. Nursing staff rated the highest assessment of professional nursing governance elements to "control over their professional practice" and reported that they participate in decisions which related mainly to the clinical practice and at the point of care level rather than administrative and managerial decisions with their first-line nurse managers. In addition, nurses may feel supported because the investment of a health governance unit which emphasized a supportive work environment. This governance unit is responsible for raising awareness, continuous education and assessment of the health care and governance standards among all health care providers, and the established hospital policies and procedures by nursing participation in its development.

The result of the present study could be supported by Wilson ${ }^{[13]}$ who stated that shared governance provides the framework for a collaborative environment for nursing leaders and direct care nurses. Together, they can formulate a partnership of shared decision-making for clinical and operational practices. Similarly, Afeef et al., ${ }^{[20]}$ reported that staff nurses' perceptions of their work environment being more closely related to the shared governance structure. Also, Fraith and Montgomery ${ }^{[21]}$ found a higher IPNG score results from involvement of staff nurses and sharing in hospital governance. In addition, Al-Faouri et al., ${ }^{[22]}$ found that nurses perceived control over their professional practice in their organization as the highest subscale and indicating that decisions shared between staff nurses and nursing management.

Our finding was in contrast to Seada \& Etway ${ }^{[23]}$ who revealed that staff nurses had lower perception of shared governance and indicated that they did not have professional control over their work environment. As well, Tourangeau et al., ${ }^{[24]}$ reported that staff nurses perceived they have the least amount of control over professional practice as well as they perceived little input or control in many areas that directly affect the patient care.

On the other hand, the current study revealed that goal setting and conflict resolution had the lowest rating of nursing staff assessment of professional nursing governance elements. This could be due to the less involvement of nursing staff with hospital and nursing management in administrative decisions such as setting the hospital and work-related mission, philosophy, and goals and most of the conflict issues are being solved by the management with little participation from nursing staff. Similarly, Mahmoud ${ }^{[25]}$ stated that nurses could participate with nursing management/administration in clinical practice decisions, however, nurses had limited ability to participate in committees that relate to strategic planning, multidisciplinary professionalism, and organizational budget. Also, Kieft et al., ${ }^{[26]}$ conducted a qualitative study that showed nurses are not always in charge and cannot every time make their own decisions about nursing issues. Additionally, they reported that if nurses are more involved in the development of nursing policies, it would have a positive influence on patient care.

In this context, Al-Faouri et al., ${ }^{[22]}$ emphasized on several factors that are essential to the success of a shared governance program, including support from managers and leaders, clear role delineation, and support for the time nurses need to participate. Also, Jacobs ${ }^{[27]}$ highlighted that the flexibility for nurses to participate in different ways leads to increased participation and strength of the shared governance structure.

\subsection{Magnet components (nursing excellence) at Alexan- dria Medical Research Institute Hospital}

The present study illustrated that nursing administrators and staff significantly gave the higher recognition than medical administrators to the following magnet components; quality of nursing care, quality improvement, structural empower- 
ment, exemplary professional practice and transformational leadership. While medical administrators gave the highest recognition to management style. These results could be explained in the light of the active and assertive role of nurses in nursing activities at all levels and trustful relationship with all hospital staff. In the same line, Cummings et al., ${ }^{[28]}$ illustrated that nurses' concern towards their workplace environment which can impact on the health and well-being of nurses and potentially contribute to the outcomes of patient care. They found various forms of leadership exerted differential effects on the nursing workforce and work environment. Also, Bretschneider et al., ${ }^{[29]}$ concluded, increasing nurses' access to information resources and decision making empowers them to effectively serve as providers and leaders in increasingly complex healthcare environments.

In this respect, $\mathrm{Al}$ Ateeque ${ }^{[30]}$ recommended that providing a work environment that magnetizes nurses and fosters excellence becomes crucial to attracting and maintaining new graduates, decreasing nurses' turnover and ensuring safe care. Hospitals should strive toward magnetic designation to have a competitive advantage in the requirements of all nurses as well as for health care providers to enjoy working in an attractive practice environment.

\subsection{Correlation and regression weight between profes- sional nursing governance and hospital magnet com- ponents}

The statistical result of standardized regression model revealed a positive association between overall professional nursing governance and magnet components. Correlation result also revealed a positive relationship between control over professional practice and overall magnet components. This finding could be related to what has been highlighted in this study for the presence of supportive leadership, work environment and structure as well as interdisciplinary relationships between nursing staff and hospital administrators in a respectful manner. The studied hospital applies a modification of the organizational structure that accommodates change and covers the nursing staff need of information and resources especially after the investment of health governance unit.

These results go in the same line with Kramer et al., and Schmalenberg and Kramer ${ }^{[31,32]}$ who highlighted that organizational structures and leadership practices are essential for a magnetic work environment and assured that control of nursing practice is one of the processes identified by magnet hospital staff nurses that is essential for developing a healthy and an attractive work environment. In many magnet organizations, the shared governance model is the cornerstone of the forces of magnetism. ${ }^{[33]}$ Similarly, Ducharme et al., ${ }^{[34]}$ found positive correlation between perceived influence over

Published by Sciedu Press professional practice environments and clinical nurses' reported engagement in essential professional nursing practice. Also, Mahmoud ${ }^{[25]}$ indicated a significant relationship between nurses' perceptions of professional shared governance and their working empowerment.

However, staff nurses may be dissatisfied with their participation in the area of goal setting and conflict resolution and committee structure which reflected negatively in the result of regression and correlation analysis. Similarly, Kramer and Schmalenberg ${ }^{[35]}$ reported that staff nurses agreed that shared governance councils and committees that lacked authority or control over professional nursing practice lead to cynicism, but there is no further exploration to identify or quantify how many of these shared governance structures lack authority or control. Green and Jordan ${ }^{[36]}$ suggested that engaging nurses in decision making, work redesign, and conflict resolution enhances nurse empowerment within the work environment since nurses have limited skills in this area. Therefore, nurses need more knowledge and training regarding conflict negotiation strategies to improve their ability to advocate for and provide quality patient care. A need was identified for nurse managers to implement empowering and developmental strategies that afford staff nurses the opportunity to have control over nursing practice and promote quality nursing care. ${ }^{[25]}$ Also, Arabi et al., ${ }^{[37]}$ emphasized nurses' influence on health policy to protect the quality of care by access to required recourses and opportunities for shared decisions.

\section{Conclusion}

In summary, the current study highlighted several important findings. The results revealed that the studied hospital has a shared governance structure in place to engage staff nurses in decision-making which make them feel control over their professional practice. A gap was identified for their participation in goal setting and conflict resolution and professional development. Using the ANCC Magnet framework gap analysis as the standard, revealed that the both medical administrators and nursing staff identified the hospital has a relatively good structure and leadership practice in place that supported shared governance and magnet recognition. Closing the identified gaps would support an infrastructure for shared governance. Further development of structural empowerment is needed. Moreover, findings support the assertion that nurse leaders are integral in enhancing professional practice environments.

Furthermore, the positive association between professional nursing governance and magnet framework components ensured the neccesiitiy of enhancing the presence of magnet forces for implementing and practicing professional nursing 
governance in the hospital.

\subsection{Strengths and limitations}

The combination of the IPNG survey and the ANCC Magnet framework to evaluate the current shared governance status was beneficial in identifying areas for improvement and achieving nursing excellence. One limitation of the study was that data were not collected as to how many of the respondents were engaged in hospital-wide committees and councils and how these numbers could be related to their satisfaction of professional nursing governance. It would have been of interest to compare responses from those who were or were not engaged in committees' activities. Also, the data collected from one hospital and the result of this study could not be generalized to all hospitals in Alexandria governorate. So, future studies need to be replicated in a wider hospitals range for more generalization. Using standardized tools for conducting the study and assessing perception at different settings are positive points could be enhanced in future studies.

\subsection{Recommendation}

The current study presented a series of recommendations and improvement strategies for professional nursing practices. Nurse executives can consider shared governance implementation in the hospital as a way to empower and engage nurses in professional practice and increase nurses' satisfaction and retention:

- More Management support is needed for increasing participation of nursing staff in work design, problemsolving, conflict resolution, committees and organizational decision-making as "key ingredients to successful organization”. To engage more direct-care nurses in committees and councils, the organization should work to reduce barriers by adjusting schedules to allow time for nurses' participation. Another way of achieving greater professional nursing engagement is to consider implementing a formal professional advancement structure, such as clinical ladders.

- Provided nursing staff with professional development and training opportunities specially for strategic planning, goal setting, and conflict management, to enhance their team work, autonomy, sense of motivation, and empowerment.

\subsection{Future research}

The current study findings taken in conjunction with the available literature suggest the need for future research studies. There is a need to develop well-planned research studies, which focus on validating the outcomes of implementing professional shared governance in hospitals. Applying a comparative research of professional nursing shared governance perception in private and governmental hospitals could identify the structural elements and work environment that leads to successful implementation of shared governance model and work empowerment.

\section{ACKNOWLEDGEMENTS}

Our deepest thanks to Professor, Dr. Gehan El-Bialy, Professor of Nursing Administration, Alexandria University, for her valuable assistance in reviewing this research article. Also, we would like to thank all participants who agreed to participate in this research study.

\section{CONFlicts OF INTEREST Disclosure}

The authors declare that there is no conflict of interest.

\section{REFERENCES}

[1] Wilson E. Evaluating shared governance for nursing excellence. Published Doctorate Dissertation. University of Nevada, Las Vegas: 2013.

[2] World Health Organization. Egypt Nursing Profile. WHO country office for Egypt. 2012. Available from: http://www . emro. who.i nt/countries/egy/index.html

[3] Cohen C. Leveraging the power of shared governance. Published Doctorate Dissertation. College of Health Sciences, Walden University; 2015.

[4] Porter-O'Grady T. Is shared governance still relevant? Journal of Nursing Administration. 2001; 4(10): 468-473. https://doi.or $\mathrm{g} / 10.1097 / 00005110-200110000-00010$

[5] Swihart D, Porter-O'Grady T. Shared governance: a practical approach to reshaping professional nursing practice. Publisher: HCPro, 2006.
[6] American Nurses Credentialing Center. The ANCC Magnet Recognition Program: Recognizing Nursing Excellence. Washington, DC: American Nurses Credentialing Center; 2008.

[7] Hess R, DesRoches C, Donelan K, et al. Perceptions of nurses in Magnet hospitals, non-Magnet hospitals, and hospitals pursuing Magnet status. Journal of Nursing Administration. 2011; 41(7/8): 315-323. https://doi.org/10.1097/NNA.0b013e31822509e2

[8] Hess R. The measurement of professional governance: Scoring guidelines and benchmarks [instrument manual]. Voorhees, NJ: Forum for Shared Governance, 2010

[9] Anthony M. Shared governance models: The theory, practice, and evidence. Online Journal of Issues in Nursing. 2004; 9(1): 138-153.

[10] KentuckyOne Health: Excellence Defined ULH \& JGBCC Nursing. The Components of Excellence, 2012 Annual Report, University of Louisville Hospital. Available from: https://www. kentuckyon ehealth.org/documents/2012NursingAR.pdf 
[11] Mouro G, Tashjian H, Bachir R, et al. Comparing nurses' perceptions of governance related to hospitals' journeys to excellence status in the middle east. NURSING ECONOMIC. 2013; 31(4): 184-189. PMid:24069718

[12] Raymond A. Decisional involvement and shared governance: perception comparisons between BSN and MSN student ratings. Published Master Thesis. California State University, Fullerton, 2011.

[13] Wilson J, Speroni K, Jones R, et al. Exploring how nurses and managers perceive shared governance. Nursing. 2014; 44(7): 19-22. ht tps://doi.org/10.1097/01. NURSE.0000450791.18473.52

[14] Abd Elkader E. Assessment of magnet professional forces as perceived by administrators and nursing staff at Mansoura International Hospital. Unpublished Master Thesis, Mansoura: Faculty of Nursing, Mansoura University; 2009.

[15] Abd Elrazek H. The relationship between nurses' perception toward the essentials of magnetism and patients' safety culture. Unpublished Master Thesis, Alexandria: Faculty of Nursing, Alexandria University; 2012.

[16] El Bialy G, Abd Elaal N. Essentials of magnetism as perceived by nurses at Alexandria German Hospital. Life Science Journal. 2013; 10(4): 2889-2899.

[17] Ahmed H. Shared Governance and its effect on nurses' work satisfaction at Assiut University Hospital. Unpublished Master Thesis, Assiut: Faculty of Nursing, Assiut University; 2012.

[18] Anderson E. A case for measuring governance. Nursing Administration Quarterly. 2011;35(3): 197-203. https ://doi.org/10.109 $7 / \mathrm{NAQ}$.0b013e3181ff3f 42

[19] Kennerly S. Effects of shared governance on perceptions of work and work environment. Nursing Economics. 2006; 14(2): 111-117.

[20] Afeef M, Fayumi W, Qudimat M. Nurses perception of shared governance. Proceeding of the Third JNC International Nursing Conference; Jordan. Amman, Jordanian Nursing Council. 2010.

[21] Fraith K, Montgomery M. Perceptions, knowledge, and commitment of clinical staff to shared governance. Nursing Administration Quarterly. 2006; 30(3): 273-284. https://doi.org/10.1097/000062 16-200607000-00012

[22] Al-Faouri I, Ali N, Essa M. Perception of Shared Governance among Registered Nurses in a Jordanian University Hospital. International Journal of Humanities and Social Science. 2014; 46(1): 254-262.

[23] Seada A, Etway E. Relationship between staff nurses' perception of professional shared governance and their job satisfaction. Journal of American Science. 2012; 8(5): 199-208.

[24] Tourangeau A, Coghlan A, Shamian J, et al. Registered nurse and registered practical nurses evaluations of their hospital practice environments and their responses to these environments. Nursing Leadership. 2005; 18(4): 54-65. https ://doi.org/10.12927/cjnl. 20 05.17835
[25] Mahmoud H. The relationship between nurses' professional shared governance and their work empowerment at Mansoura University and Specialized Medical Hospitals. Journal of Biology, Agriculture and Healthcare. 2016; 6(18): 13-21.

[26] Kieft R, Brouwer B, Francke A, et al. How nurses and their work environment affect patient experiences of the quality of care: a qualitative study. BMC Health Services Research. 2014; 14(1): 249. https://doi.org/10.1186/1472-6963-14-249

[27] Jacobs C, Ward C. Empowering frontline nurses to transform shared governance. Nursing. 2012; 42(7): 18-20. https ://doi.org/10 $.1097 / 01$. NURSE. 0000415321.70217.0d

[28] Cummings G, MacGregor T, Davey M, et al. Leadership styles and outcome patterns for the nursing workforce and work environment: A systematic review. International Journal of Nursing Studies. 2010; 47(3): 363-385. https://doi.org/10.1016/j.ijnurstu. 200 9.08 .006

[29] Bretschneider J, Glenn-West R, Green-Smolenski J, et al. Strengthening the Voice of the Clinical Nurse: The Design and Implementation of a Shared Governance Model. Nursing Administration Quarterly. 2010; 34(1): 41-48. https : //doi .org/10.1097/NAQ. 0b013e31 $81 \mathrm{c} 95 \mathrm{f} 5 \mathrm{e}$

[30] Al Ateeq E. The relationship between nurses' perceptions of work environment and their perceptions of patient safety culture. Published Doctoral Dissertation, Faculty of Nursing, George Mason University; 2008.

[31] Kramer M, Schmalenberg C, Maguire P. Nine structures and leadership practices essential for a magnetic (healthy) work environment. Nursing Administration Quarterly. 2010; 34(1): 4-17. https : //doi.org/10.1097/NAQ.0b013e3181c95ef4

[32] Schmalenberg C, Kramer M. Essentials of a productive nurse work environment. Nursing Research. 2008; 57(1): 2-13. https ://doi. org/10.1097/01. NNR.0000280657.04008.2a

[33] Barden A, Griffin M, Donahue M, et al. Shared governance and empowerment in registered nurses working in a hospital setting. Nursing Administration Quarterly. 2011; 35(3): 212-218. https : //doi.org/10.1097/NAQ.0b013e3181ff3845

[34] Ducharme M, Bernhardt J, Padula CA, et al. Leader influence, the professional practice environment, and nurse engagement in essential nursing practice. Journal of Nursing Administration. 2017; 47(7-8): 367-375. https://doi .org/10.1097/NNA . 0000000000000497

[35] Kramer M, Schmalenberg C. Essentials of a magnetic work environment: Part 2. Nursing. 2004; 34(7): 44-47. https ://doi . org/10 .1097/00152193-200407000-00048

[36] Green A, Jordan C. Common denominators: Shared governance and work place advocacy-strategies for nurses to gain control over their practice. Online Journal of Issues in Nursing. 2004; 9(1): 10.

[37] Arabi A, Rafii F, Cheraghi M, et al. Nurses' policy influence: A concept analysis. Iran Journal of Nursing Midwifery Research. 2014; 19(3): 315-322. PMid:24949073 